\title{
A Prognostic Examination of Employee Engagement from its Historical Roots
}

\author{
D. Pradeep Kumar and G. Swetha
}

\begin{abstract}
In a world that is changing both in terms of the global nature of work and the diversity of the workforce, engaged employees may be a key to competitive advantage. Companies that understand the conditions that enhance employee engagement will have accomplished something that competitors will find very difficult to imitate. This article throws light on the following objectives:- 1.To define Employee Engagement 2. To differentiate Employee Engagement from other constructs 3. To study Antecedents and Consequences of Employee Engagement 4. To analyze the Measurement issues of Employee Engagement 5.To present an overview on researching Employee Engagement 6. To conclude and recommend for better Employee Engagement in organizations
\end{abstract}

Index Terms-Burn out, Disengagement, Employee Engagement, Job Involvement.

\section{INTRODUCTION}

Employee engagement is a key business driver for organizational success. High levels of engagement in domestic and global firms promote retention of talent, foster customer loyalty and improve organizational performance and stakeholder value. A complex concept, engagement is influenced by many factors-from workplace culture, organizational communication and managerial styles to trust and respect, leadership and company reputation. For today's different generations, access to training and career opportunities, work/life balance and empowerment to make decisions are important. Thus, to foster a culture of engagement, HR leads the way to design, measure and evaluate proactive workplace policies and practices that help attract and retain talent with skills and competencies necessary for growth and sustainability.

The authors have taken up the analysis of the secondary data on Employee Engagement with the following objectives:

1) To define Employee Engagement

2) To differentiate Employee Engagement from other constructs

3) To study Antecedents and Consequences of Employee Engagement

4) To analyze the Measurement issues of Employee Engagement

Manuscript received April 28, 2011.

D. Pradeep Kumar is Professor \& Head, Department of Management Studies, at Madanapalle Institute of Technology \& Science, Madanapalle, A.P.(e-mail: pradeep4a2@yahoo.co.in)

G. Swetha , Assistant Professor, S.V.College of Engineering, Tirupati ,A.P.(e-mail:swetha_reddi84@yahoo.com)
5) To present an overview on researching Employee Engagement

6) To conclude and recommend for better Employee Engagement in organizations. Definitions of Employee Engagement

As there are numerous definitions of Employee engagement which leads to ambiguity. Different definitions of employee engagement was explained by different protocol. In addition, unless employee engagement can be universally defined and measured, it cannot be managed, nor can it be known if efforts to improve it are working (Ferguson 2007). This highlights the problems of comparability caused by differences in definition.

- Kahn (1990:694) defines employee engagement as "the harnessing of organization members' selves to their work roles; in engagement, people employ and express themselves physically, cognitively, and emotionally during role performances",

- Most often employee engagement has been defined as emotional and intellectual commitment to the organization (Baumruk 2004 ${ }^{2}$, Richman $2006^{3}$ and Shaw 2005 ${ }^{4}$ ).

- Truss et al (2006) define employee engagement simply as 'passion for work', a psychological state which is seen to encompass the three dimensions of engagement discussed by Kahn (1990), and captures the common theme running through all these definitions 5 .

- Harter, Schmidt and Hayes (2002) define employee engagement as "the individual's involvement and satisfaction with as well as enthusiasm for work" (p. 269) ${ }^{6}$.

- Lucey, Bateman and Hines (2005) interpret the Gallup Engagement Index as measuring "how each individual employee connects with your company and how each individual employee connects with your customers" (p.12). They call the opposite of this emotionally unemployed ${ }^{7}$.

- DDI (2005) uses the definition "The extent to which people value, enjoy and believe in what they do" (p1). DDI also states that its measure is similar to employee satisfaction and loyalty 8 .

- Fleming, Coffman and Harter (2005) (Gallup Organization researchers) use the term committed employees as a synonym for engaged employees ${ }^{9}$.

- Gallup's Human Sigma website (2005) likens employee engagement to the concept of customer engagement, which has the dimensions of confidence, integrity, pride and passion $^{10}$.

- Wellins and Concelman (2004) call employee engagement "the illusive force that motivates employees to higher levels of performance" (p.1) ${ }^{11}$.

- Robinson, Perryman and Hayday (2004) define 
engagement as "a positive attitude held by the employee towards the organization and its values ${ }^{12}$.

- The Business Communicator $(2005)^{13}$ reports definitions of engagement from three people they label experienced employee engagement practitioners. Those three definitions are, as follows:

1) Engagement is two sides of a coin, the knowledge needed to do one's job effectively and the motivation to apply that knowledge.

2) Increasing workforce dedication to achieve a business outcome.

3) Employee engagement is a social process by which people become personally implicated in strategy and change in their daily work.

\section{ENGAGEMENT VS OTHER CONSTRUCTS}

Employee Engagement is compared with the following Constructs. They are:-

- Organizational Commitment

- Organizational Citizenship Behavior (OCB)

- Job Involvement and flow

- Attitude or Behavior

- Individual or group

- Job Satisfaction

- Job Involvement

It would appear that there are sufficient grounds for arguing that engagement is related to, but distinct from, other constructs in organizational behaviour (Saks 2006) ${ }^{14}$. For example, Robinson et al (2004) ${ }^{15}$ state that:

"...engagement contains many of the elements of both commitment and OCB but is by no means a perfect match with either. In addition, neither commitment nor OCB reflect sufficiently two aspects of engagement - its two way nature, and the extent to which engaged employees are expected to have an element of business awareness."

Organizational citizenship behaviors (OCBs) are discretionary behaviors that are beyond formal obligations. OCB, an outcome of the attitudes of job satisfaction and organizational commitment, is similar to the definitions in the engagement literature of being respectful of and helpful to colleagues and willingness to go the extra mile (Robinson, et al., 2004), or working longer hours, trying harder, accomplishing more and speaking positively about the organization (Wellins \& Concelman, 2004).

Saks (2006) argues that organizational commitment also differs from engagement in that it refers to a person's attitude and attachment towards their organization, whilst it could be argued that engagement is not merely an attitude; it is the degree to which an individual is attentive to their work and absorbed in the performance of their role. In addition, while OCB involves voluntary and informal behaviours that can help co-workers and the organization, the focus of engagement is one's formal role performance rather than purely extra-role and voluntary behavior.

According to May et al (2004) ${ }^{16}$ engagement is most closely associated with the constructs of job involvement and 'flow' (Csikszentmihalyi 1990) ${ }^{17}$. Job involvement is defined as 'a cognitive or belief state of psychological identification' (Kanungo 1982:342) ${ }^{18}$.
Problems Associated with the Construct of Employee Engagement

Looking across the definitions in the above list, four problems emerge to the authors. The problems, which will be elaborated upon in the following sections, are, as follows:

- The definitions are not clear as to whether engagement is an attitude or a behavior.

- The definitions are not clear as to whether engagement is an individual or a group level phenomenon.

- The definitions do not make clear the relationship between engagement and other well-known and accepted constructs.

- There are measurement issues that obscure the true meaning of the construct.

\section{Attitude or behavior?}

The job attitude literature makes a distinction between attitudes (affective responses to an object or situation), behavioral intentions based on attitudes, and actual behaviors (Roznowsky \& Hulin, 1992) ${ }^{19}$. The above definitions reveal that the construct of employee engagement has been ill-defined. First of all, most of the authors do not distinguish between attitudes and behaviors, mixing examples of both in their definitions.

\section{Individual or roup?}

The construct of employee engagement lacks clarity as to the level of analysis it represents. The major strength of the argument made by the Gallup researchers in all their publications is the relationship of engagement to productivity, profitability, employee retention, and customer service at the business unit level (hospital, hotel, factory, etc.). Does this mean that employee engagement is a group-level phenomenon? If engagement is being used as a group level phenomenon, good research methods require that it be subjected to tests of within-group and between-group variance (Dansereau, Alutto \& Yammarino, 1998) ${ }^{20}$.

\section{Job Satisfaction}

Job satisfaction, a widely researched construct, is defined as a pleasurable or positive emotional state resulting from the appraisal of one's job or job experiences (Locke \& Henne, 1986) ${ }^{21}$. Harter, et al. $(2002)^{22}$ begin their discussion of engagement by using the term engagement-satisfaction, but drop the satisfaction from the term early in their article. It has been found that while the relationship between job satisfaction and performance is weak at the individual level, but is stronger at the aggregate level (Ostroff, 1992) ${ }^{23}$.

\section{Job involvement.}

Job involvement is the degree to which one is cognitively preoccupied with, engaged in and concerned with one's present job (Paullay, et al., 1994) ${ }^{24}$. Pfeffer (1994) ${ }^{25}$ argues that individuals' being immersed in their work is a primary determinant of organizational effectiveness. Job involvement has been shown to be related to OCBs and job performance (Diefendorff, Brown, Kamin \& Lord, 2002) ${ }^{26}$. In the employee engagement literature, Wellins and Concelman $(2004)^{27}$ use the term job ownership as a synonym of engagement 


\section{ANTECEDENTS AND CONSEQUENCES OF EMPLOYEE ENGAGEMENT}

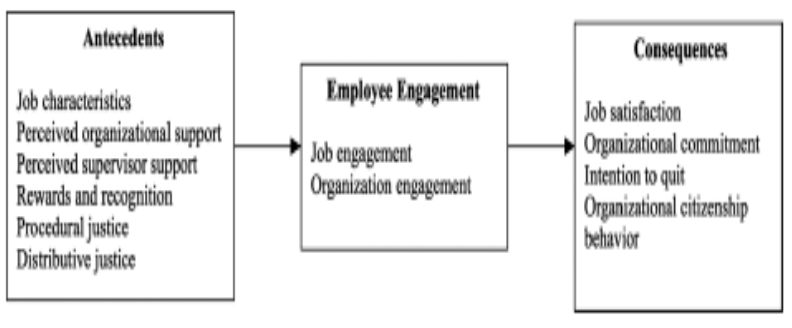

Antecedents of Employee Engagement

\section{A. Job characteristics}

Psychological meaningfulness involves a sense of return on investments of the self-in-role performances (Kahn, 1992). According to Kahn (1990, 1992), psychological meaningfulness can be achieved from task characteristics that provide challenging work, variety, allow the use of different skills, personal discretion, and the opportunity to make important contributions. This is based on Hackman and Oldham's (1980) ${ }^{28}$ job characteristics model and in particular, the five core job characteristics (i.e. skill variety, task identity, task significance, autonomy, and feedback)

\section{B. Perceived organizational and supervisor support}

Two variables that are likely to capture the essence of social support are perceived organizational support (POS) and perceived supervisor support (PSS). POS refers to a general belief that one's organization values their contribution and cares about their well-being (Rhoades and Eisenberger, 2002) ${ }^{30}$. The basic premise of organizational support research is SET. The Social Exchange Theory (SET) perspective is that employees who are provided with enriched and challenging jobs will feel obliged to respond with higher levels of engagement. SET argues that obligations are generated through a series of interactions between parties who are in a state of reciprocal interdependence. A basic principle of SET is that relationships evolve over time into trusting, loyal, and mutual commitments as long as the parties abide by certain 'rules' of exchange (Cropanzano and Mitchell 2005).

In particular, POS creates an obligation on the part of employees to care about the organization's welfare and to help the organization reach its objectives (Rhoades et al., $2001)^{31}$. PSS is also likely to be an important predictor of employee engagement. In fact, a lack of support from supervisors has been found to be an especially important factor linked to burnout (Maslach et al., 2001). When employees have high perceptions of justice in their organization, they are more likely to feel obliged to also be fair in how they perform their roles by giving more of themselves through greater levels of engagement.

\section{Rewards and recognition}

Kahn (1990) reported that people vary in their engagement as a function of their perceptions of the benefits they receive from a role. Maslach et al. $(2001)^{29}$ have also suggested that while a lack of rewards and recognition can lead to burnout, appropriate recognition and reward is important for engagement

\section{Distributive and procedural justice}

The safety dimension identified by Kahn (1990) involves social situations that are predictable and consistent. For organizations, it is especially important to be predictable and consistent in terms of the distribution of rewards as well as the procedures used to allocate them. While distributive justice pertains to one's perception of the fairness of decision outcomes, procedural justice refers to the perceived fairness of the means and processes used to determine the amount and distribution of resources (Colquitt, 2001; Rhoades et al., 2001). A review of organizational justice research found that justice perceptions are related to organizational outcomes such as job satisfaction, organizational commitment, organizational citizenship behavior, withdrawal, and performance (Colquitt et al.,2001). However, previous research has not tested relationships between fairness perceptions and employee engagement

\section{Consequences of Employee Engagement}

\section{A. Job Satisfaction}

Job satisfaction, a widely researched construct, is defined as a pleasurable or positive emotional state resulting from the appraisal of one's job or job experiences (Locke \& Henne, $1986)^{32}$. It has been found that while the relationship between job satisfaction and performance is weak at the individual level, but is stronger at the aggregate level (Ostroff, 1992).

\section{B. Organizational Commitment}

This also differs from engagement in that it refers to a person's attitude and attachment towards their organization. Engagement is not an attitude; it is the degree to which an individual is attentive and absorbed in the performance of their roles.

\section{Intention to Quit}

Intention to quit includes basically the reasons why employees are going to quit the job, and what factors made the employee to leave the organization. The engaged employees do not frequently quit the job.

\section{Organizational Citizenship Behavior}

OCB involves voluntary and informal behaviors that can help co-workers and the organization, the focus of engagement is one's formal role performance rather than extra-role and voluntary behavior. According to Maslach et al. (2001), six areas of work-life lead to burnout and engagement: workload, control, rewards and recognition, community and social support, perceived fairness, and values. They argue that job engagement is associated with a sustainable workload, feelings of choice and control, appropriate recognition and reward, a supportive work community, fairness and justice, and meaningful and valued work.

The driving force behind the popularity of employee engagement is that it has positive consequences for organizations. As indicated earlier, there is a general belief that there is a connection between employee engagement and business results (Harter et al., 2002) ) $^{33}$. However, engagement is an individual-level construct and if it does lead to business results, it must first impact individual-level outcomes. Along these lines, there is reason to expect employee engagement to 
be related to individuals' attitudes, intentions, and behaviors.

\section{MeASuREMEnt Issues of EMPLOYee ENGAGEMENT}

Gallup came up with Q. 12, a twelve-question survey that identifies strong feelings of employee engagement. They have identified 12 questions that most effectively measure the links (the Gallup Q12) ${ }^{34}$.

1) Do you know what is expected of you at work?

2) Do you have the materials and equipment you need to do your work right?

3) At work, do you have the opportunity to do what you do best every day?

4) In the last seven days, have you received recognition or praise for doing good work?

5) Does your supervisor, or someone at work, seems to care about you as a person?

6) Is there someone at work who encourages your development?

7) At work, do your opinions seem to count?

8) Does the mission/purpose of your company make you feel your job is important?

9) Are your associates (fellow employees) committed to doing quality work?

10) Do you have a best friend at work?

11) In the last six months, has someone at work talked to you about your progress?

12) In the last year, have you had opportunities at work to learn and grow?

\section{A. The Engagement Index:}

The first measurement tool is JRA six item engagement index. The JRA employee engagement index has been validated across many thousands of New Zealand employees since its first use in $2000^{35}$.

This is a simple and focused tool that uses six items to assess the rational-emotional-behavioral components of employee engagement. The six questionnaire items are:

a) I look for ways to do my job more effectively

b) Overall, I'm satisfied with my job

c) I take an active interest in what happens in this organization

d) I feel inspired to go the extra mile to help this organization succeed

e) I feel a sense of commitment to this organization

f) Overall, I would recommend this organization as a great place to work

The Corporate Leadership Council ${ }^{36}$ uses the following four questions:

- I am proud to work at COMPANY

- Overall my satisfaction with COMPANY is high

- I would recommend COMPANY as a great place to work

- If offered a similar position and compensation at another company I would stay at COMPANY

\section{AN OVERVIEW ON RESEARCHING EMPLOYEE ENGAGEMENT}

One of the most influential studies of engagement was carried out by Kahn (1990). Conceptually, Kahn began with the work of Goffman $(1961)^{37}$ who proposed that, "people's attachment and detachment to their role varies" (Kahn 1990:694). However, Kahn argued that Goffman's work focused on fleeting face-to-face encounters, while a different concept was needed to fit organizational life, which is "ongoing, emotionally charged, and psychologically complex" (Diamond and Allcorn 1985) ${ }^{38}$.

To gain further understanding of the varying levels of attachment individuals expressed towards their roles, Kahn (1990) examined several disciplines. It was found that psychologists (Freud 1922) ${ }^{39}$, sociologists (Goffman 1961, Merton $1957^{40}$ ) and group theorists (Slater $1966^{41}$, Smith and Berg $1987^{42}$ ) had all recognized the idea that individuals are naturally hesitant about being members of ongoing groups and systems. As a result they "seek to protect themselves from both isolation and engulfment by alternately pulling away from and moving towards their memberships" (Kahn 1990). The terms Kahn (1990) uses to describe these calibrations are 'personal engagement' and 'personal disengagement', which refer to the "behaviors by which people bring in or leave out their personal selves during work role performances" (Kahn 1990:694). These terms developed by Kahn (1990) integrate previous ideas taken from motivation theories that people need self-expression and self-employment in their work lives as a matter of course (Alderfer 1972 $2^{43}$, Maslow 1954 $4^{44}$ ).

Kahn undertook a qualitative study on the psychological conditions of personal engagement and disengagement by interviewing summer camp counselors and staff at an architecture firm about their moments of engagement and disengagement at work. He defined disengagement as the decoupling of the self within the role, involving the individual withdrawing and defending themselves during role performances (May et al 2004). Disengaged employees displayed incomplete role performances and were effortless, automatic or robotic (Kahn 1990). Kahn found that there were three psychological conditions related with engagement or disengagement at work: meaningfulness, safety, and availability. He argued that people asked themselves three fundamental questions in each role situation: (i) How meaningful is it for me to bring myself into this performance; (ii) How safe is it to do so?; and (iii) How available am I to do so? He found that workers were more engaged at work in situations that offered them more psychological meaningfulness and psychological safety, and when they were more psychologically available.

In the only study to empirically test Kahn's (1990) model, May et al (2004) found that meaningfulness, safety, and availability were significantly related to engagement. They also found job enrichment and role fit to be positive predictors of meaningfulness; rewarding coworker and supportive supervisor relations were positive predictors of safety, while adherence to co-worker norms and self-consciousness were negative predictors. Resources were a positive predictor of psychological availability, while participation in outside activities was a negative predictor. Overall, meaningfulness was found to have the strongest relation to different employee outcomes in terms of engagement. 
An alternative model of engagement comes from the 'burnout' literature, which describes job engagement as the positive antithesis of burnout, noting that burnout involves the erosion of engagement with one's job (Maslach et al $2001^{45}$ ). According to Maslach et al, six areas of work-life lead to either burnout or engagement: workload, control, rewards and recognition, community and social support, perceived fairness and values. They argue that job engagement is associated with a sustainable workload, feelings of choice and control, appropriate recognition and reward, a supportive work community, fairness and justice, and meaningful and valued work. Like burnout, engagement is expected to mediate the link between these six work-life factors and various work outcomes. May et al's (2004) findings support Maslach et al's (2001) notion of meaningful and valued work being associated with engagement, and therefore it is important to consider the concept of 'meaning'.

According to Holbeche and Springett $(2003)^{46}$, people's perceptions of 'meaning' with regard to the workplace are clearly linked to their levels of engagement and, ultimately, their performance. They argue that employees actively seek meaning through their work and, unless organizations try to provide a sense of meaning, employees are likely to quit. The research findings suggest that many people experience a greater search for meaning in the workplace (70 per cent) than in life in general (ibid). There are numerous possible reasons for this, for example, it may be because people generally spend longer at work than on other parts of their lives. Holbeche and Springett (2003) argue that high levels of engagement can only be achieved in workplaces where there is a shared sense of destiny and purpose that connects people at an emotional level and raises their personal aspirations.

Kahn's (1990) and Maslach et al's (2001) models indicate the psychological conditions or antecedents that are necessary for engagement, but they do not fully explain why individuals will respond to these conditions with varying degrees of engagement. According to Saks (2006), a stronger theoretical rationale for explaining employee engagement can be found in social exchange theory (SET). SET argues that obligations are generated through a series of interactions between parties who are in a state of reciprocal interdependence. A basic principle of SET is that relationships evolve over time into trusting, loyal, and mutual commitments as long as the parties abide by certain 'rules' of exchange (Cropanzano and Mitchell 2005) ${ }^{47}$. Such rules tend to involve reciprocity or repayment rules, so that the actions of one party lead to a response or actions by the other party. For example, when individuals receive economic and socio-emotional resources from their organization, they feel obliged to respond in kind and repay the organization (ibid). This is consistent with Robinson et al's (2004) description of engagement as a two-way relationship between the employer and employee.

Saks (2006) argues that one way for individuals to repay their organization is through their level of engagement. In other words, employees will choose to engage themselves to varying degrees and in response to the resources they receive from their organization. Bringing oneself more fully into one's work roles and devoting greater amounts of cognitive, emotional, and physical resources is a very profound way for individuals to respond to an organization's actions, as suggested earlier by the work of Kahn (1990). Thus, employees are more likely to exchange their engagement for resources and benefits provided by their organization.

In summary, Social Exchange Theory, SET provides a theoretical foundation to explain why employees choose to become more or less engaged in their work and organization. In terms of Kahn's (1990) definition of engagement, employees feel obliged to bring themselves more deeply into their role performances as repayment for the resources they receive from their organization. When the organization fails to provide these resources, individuals are more likely to withdraw and disengage themselves from their roles. Thus, the amount of cognitive, emotional, and physical resources that an individual is prepared to devote in the performance of their work role may be contingent on the economic and socio-emotional resources received from the organization.

In recent years, more studies have begun to look at the antecedents and consequences of employee engagement. For example, Saks (2006) found a distinction between two types of engagement, job engagement and organization engagement, which he argues are related but distinct constructs. In addition, he argued that the relationships between both job and organization engagement, and their antecedents and consequences differed in a number of ways, suggesting that the psychological conditions that lead to job and organization engagement, as well as their consequences, are not the same. Whilst this study has provided a new insight into employee engagement, it is important to note the survey was completed by a small sample of 102 employees in Canada. Therefore, the results may not be generalisable to employees in the UK, for example, as definitions of engagement vary in different countries and national differences may play a part in what leads to engagement in the first place. Nevertheless, it adds a new insight into the existing body of literature as it is the first study to make a distinction between job and organization engagement and to measure a variety of antecedents and consequences of job and organization engagement; previous research has focused primarily on engagement at the individual level.

Practitioners and academics tend to agree that the consequences of employee engagement are positive (Saks 2006). There is a general belief that there is a connection between employee engagement and business results; a meta-analysis conducted by Harter et al (2002:272) confirms this connection. They concluded that, “...employee satisfaction and engagement are related to meaningful business outcomes at a magnitude that is important to many organizations". However, engagement is an individual-level construct and if it does lead to business results, it must first impact individual-level outcomes. Therefore, there is reason to expect employee engagement is related to individuals' attitudes, intentions, and behaviors. Although neither Kahn (1990) nor May et al (2004) included outcomes in their studies, Kahn (1992) proposed that high levels of engagement lead to both positive outcomes for individuals, (eg quality of people's work and their own experiences of doing that work), as well as positive organizational-level outcomes (eg the growth and productivity of organizations).

The Gallup Organization(2004) ${ }^{48}$ found critical links 
between employee engagement, customer loyalty, business growth and profitability. They compared the scores of these variables among a sample of stores scoring in the top 25 per cent on employee engagement and customer loyalty with those in the bottom 25 per cent. Stores in the bottom 25 per cent significantly under-performed across three productivity measures: sales, customer complaints and turnover. Gallup cites numerous similar examples. The International Survey Research (ISR) ${ }^{49}$ team has similarly found encouraging evidence that organizations can only reach their full potential through emotionally engaging employees and customers (ISR 2005).

In an extension of the Gallup findings, Ott $(2007)^{50}$ cites Gallup research, which found that higher workplace engagement predicts higher earnings per share (EPS) among publicly-traded businesses. When compared with industry competitors at the company level, organizations with more than four engaged employees for every one actively disengaged, experienced 2.6 times more growth in EPS than did organizations with a ratio of slightly less than one engaged worker for every one actively disengaged employee. The findings can be considered as reliable as the variability in differing industries was controlled by comparing each company to its competition, and the patterns across time for EPS were explored due to a 'bouncing' increase or decrease which is common in EPS (Ott 2007).

Whilst this research does not show investors and business leaders exactly what organizations are doing on a day-to-day basis to develop engaged employees, the findings do demonstrate differences in overall performance between companies, and Gallup's meta-analyses present strong evidence that highly engaged workgroups within companies outperform groups with lower employee engagement levels, and the recent findings reinforce these conclusions at the workgroup level. The meta-analysis study shows that top-quartile business units have 12 percent higher customer advocacy, 18 per cent higher productivity, and 12 per cent higher profitability than bottom-quartile business units. In contrast, bottom-quartile business units experience 31 per cent to 51 per cent more employee turnover and 62 per cent more accidents than those in the top quartile of workplace engagement. This research into EPS provides a degree of proof that employee engagement correlates to crucial business outcomes.

\section{SUMMARY AND CONCLUSIONS}

This literature review has revealed that employee engagement has been conceptualised in many different ways. There is no single agreed definition and research has shown that, however engagement is defined, it is a multi-faceted construct (Kahn, 1990). The existence of various conceptualisations makes the state of knowledge around employee engagement difficult to determine, as each piece of research is undertaken under a different protocol, using different measures of engagement under different circumstances. Despite this potential problem, a similar pattern was found by all regardless of the country or context where the research was undertaken; the highest numbers of employees were found in the 'not engaged' category. This finding is disappointing, although perhaps not very surprising, and clearly many people do not enjoy going to work and gain little meaning from what they do for a living.

People's perceptions of meaning with regard to the workplace has connections with how engaged they are and their level of performance (Holbeche and Springett 2003). Findings suggest people seek more meaning in their day-to-day work than they do in their personal lives. This implies employers should be seeking to make work meaningful by finding out what matters to their employees, especially since evidence suggests that meaningfulness impacts not only on the individual, but also on the bottom line (Holbeche and Springett 2003). Research has also suggested a connection between employee engagement and business results, e.g. the Gallup Organization cite numerous examples of increased corporate profitability due to increased employee engagement.

There is clear evidence in the psychological literature of the effect of individual differences on work performance. Kahn (1990) suggested that individual differences shape a person's nature, which in turn, affects their ability to personally engage or disengage in all or some types or role performances. Furthermore, perception and personality have been suggested to be key influences on how individuals respond, thus shaping and directing how engaged they are. Evidence also suggests that employee engagement is related to emotional experiences and wellbeing (May et al 2004). Researchers have found that emotional factors are linked to an individual's personal satisfaction and the sense of inspiration and affirmation they get from their work and from being part of their organization (Towers Perrin 2003). However a considerable number of employees agree that their company is not a good place to work, suggesting they are emotionally unhappy, whilst others argue emotions should not be allowed to flow free, and that employees are more productive when their emotions are managed (Holbeche and Springett 2003).

Personal relationships have also been found to impact work engagement. Research has indicated that family stress is related to work stress. However, the causal relationship between the two variables is unclear. Relationships within the workplace have also been found to have an impact on 'meaningfulness', which relates to engagement. Locke and Taylor $(1990)^{51}$ indicated that such findings point to the relatedness needs individuals possess, arguing individuals who have rewarding interpersonal interactions with their co-workers also should experience greater meaning in their work. Differences in gender have also been found to impact how engaged individuals are. Evidence shows that women tend to find more fulfillment in their jobs and are more engaged than men (Johnson 2005) ${ }^{52}$, although there is no evidence that this finding is not generalisable across the globe. However, such findings need to be treated with some degree of caution. Demographic factors alone cannot predict an individual's propensity to be engaged. More significant here is the way in which people are managed. Management style, employee voice and job design impact on people's level of engagement, regardless of demographic variables.

Engaged employees were found to be almost three times 
more likely to feel their work lives positively affected their physical health than those employees who were actively disengaged, although the causal relationship between engagement and wellbeing is unclear. Nevertheless, this does not change the implication that engaged employees are more likely than others to view their jobs as healthy.

An individual's intention to leave their organization is generally regarded as an important measure of how they are feeling about their work. Engaged employees are likely to have a greater attachment to their organization (Schaufeli and Bakker $2004^{53}$; Truss et al $2006^{54}$ ). The implication of this is twofold. Whilst engaging employees can help to reduce an organization's turnover and recruitment costs, it has also been found that the longer employees stay with an organization, the less engaged they become (Ferguson $2007^{55}$ and Truss et al 2006). Such evidence stresses the importance of engagement and ensuring employees are engaged in the long term in what they do by addressing issues, which have been found to matter, rather than letting the employee-employer relationship become 'stale'.

It has been argued that employee engagement is only meaningful if there is a more genuine sharing of responsibility between management and employees over issues of substance (Purcell et al 2003) ${ }^{56}$. One of the main drivers of employee engagement was found to be employees having the opportunity to feed their views upwards. The evidence surrounding whether employers provide enough opportunities for feedback is mixed. Critics argue where employee involvement initiatives do exist, control still resides in the hands of management, with very limited power being given to employees. Nevertheless, research shows where employees have been given control over how to do their work, they are more likely to focus harder on what they are doing.

Engaged employees are also more likely to display discretionary behaviour. Engagement has been found to be closely linked to feelings and perceptions around being valued and involved, which in turn generates the kinds of discretionary effort that lead to enhanced performance (Konrad 2006) ${ }^{57}$. Such evidence implies that management needs to share control and allow employees to influence important decisions. If they do not, they risk having a workforce, which is not, and cannot be, engaged.

\section{RECOMMENDATIONS}

- Future research should attempt to flesh out the types of factors that are the most important for engagement such as flexible work arrangements, training programmes, and incentive rewards in different roles, jobs, organizations and groups.

- Managers can attempt to maintain a high level of engagement, employees experience at the beginning of their employment throughout their entire period of employment by understanding clearly what predicts engagement for those individuals.

- Future researchers should create and use 'actionable' surveys, whereby the results indicate not just levels of engagement, but also where the problem areas lie and what, in an employee's opinion, should be done to eliminate the barriers to engagement.

- Future research could also consider individual differences as variables that might predict employee engagement. Several personality variables, such as self-esteem, have been found to be related to the concept of 'burnout'; so this might also be important for engagement. Another area for future research is to study the potential effect of managerial interventions on employee engagement. There is already some existing evidence which suggests that exchange-inducing interventions can remind employees of a sense of obligation making them feel obliged to reciprocate (Ganzach et al 2002).

- Therefore, organizations that wish to improve employee engagement should focus on employees' perceptions of the support they receive from their organization. Organizations which conduct surveys and suggestion programmes, for example, address employees' needs and concerns and those which offer flexible working arrangements, for example, demonstrate caring and support; all of which may cause employees to reciprocate with higher levels of engagement.

- Research evidence shows that engagement and an employee's intention to stay with their organization are influenced by the relationships held at work and the behaviors experienced. Therefore, management must be able to develop a sense of community and ensure favorable behaviors are displayed, such as trusting employees by giving them autonomy to make their own decisions. However, the literature indicates that it is not just what managers do that is important; collegial relations are also important.

- Discretionary behaviour has been revealed to be an important element that is correlated with engagement. However, a significant majority find their skills are not fully utilized in the workplace and opportunities to engage in discretionary behaviour are denied. This again suggests that management need to pay more attention to job design, creating more opportunity for people to contribute.

- Research on emotions and wellbeing points to a link between positive feelings at work and levels of engagement. Furthermore, if management pay close attention to happiness at work, they will benefit from well-functioning employees, whilst at the same time enhancing the prospect of future resourcefulness. Organizations are more likely to see results by fostering positive emotions rather than simply concentrating on negative emotions and dealing with problems.

- Employers can increase employee engagement by going beyond downward communication and making sure that people are not just treated as employees; instead they should be treated as valued individuals, as the research on individual differences suggests.

\section{STEPS TO IMPROVE EMPLOYEE ENGAGEMENT58}

\section{A. Focus on the long term:}

- While many of these organizations did cost-cutting and 
reductions in staff, they made changes consistent with their principles and values and without losing sight of their overall goals.

\section{B. Obtain buy-in from leadership:}

- Engagement is a top priority for leaders at companies that saw improved engagement scores. Leaders at these organizations were visible and provided ongoing updates to reduce employee uncertainty and stress. They also created excitement among employees about the future of the organization (82 percent compared to 51 percent at other companies).

\section{Implement measurable actions:}

- Successful organizations use employee information as a call to action rather than an assessment. They define specific and measurable actions and take steps in areas where the organization will see a clear impact.

\section{D.Involve all stakeholders:}

- Organizations with improved engagement understand that creating a "high engagement" environment requires the involvement of multiple stakeholders - the organization (leadership, policies and program), managers and employees. They communicate to these stakeholders to ensure everyone is clear on their role in the process and on the employment proposition.

\section{E. Understand key employee segments:}

- Successful organizations understand that not all employees are necessarily equal. They focus on key segments and critical talent so that they're able to engage or re-engage them once the job market improves.

\section{F. Utilize a broader array of information and analytics:}

- Hewitt's analysis shows that 34 percent of organizations help employees through the on-boarding process to minimize the dip in engagement most organizations see in the first year of employment. Additionally, almost three quarters conduct exit surveys to understand why employees are leaving and proactively identify potential hot spots.

\section{RECOMMENDATIONS FOR INCREASING ENGAGEMENT ORGANISATIONAL ACTION59}

Identified below are just some considerations for organizational action that can enhance employee engagement

- Clarify: Be clear about the organizations strategic direction, what it means for your employees and how it impacts on what they do and how they do it

- Communicate: Be creative in how the organization communicates, give people a voice, create an environment where people can ask questions, encourage team huddles, provide opportunities to talk to other functions, face-to-face communication, open door policies

\section{G. Develop :}

- Support development opportunities, encourage self development, clarify learning opportunities, provide stretching roles and tasks

H. Provide:

- Allow people to grow, give them the freedom to do what's right, provide the right resources

I. Involve:

- Design innovative ways to involve employees in planning and decision making, welcome challenge and ideas - dragons den challenges for example

J. Lead:

- Develop leadership style that is approachable, available, open, authentic and supportive

K. Make work meaningful:

- -Provide challenge and interest, be clear about what is important, show how individuals can contribute in the context of the organizations goals

L. Manage:

- Treat people as individuals, provide feedback, enable opportunities for growth, coaching and guidance, be honest and make time for others

M. Reward:

- Give recognition, celebrate success, acknowledge individuals Contributions

N. Socialize:

- Encourage having fun - arrange events, X-factor style competitions, sports teams.

O. In Closing:

- He level of engagement determines whether people are productive and stay with the organization-or move to the competition. Research highlights that the employee connection to the organizational strategy and goals, acknowledgment for work well done, and a culture of learning and development foster high levels of engagement. Without a workplace environment for employee engagement, turnover will increase and efficiency will decline, leading to low customer loyalty and decreased stakeholder value. Ultimately, because the cost of poor employee engagement will be detrimental to organizational success, it is vital for HR to foster positive, effective people managers along with workplace policies and practices that focus on employee well-being, health and work/life balance.

\section{REFERENCES}

[1] Kahn, W.A. (1990) 'Psychological conditions of personal engagement and disengagement at work', Academy of Management Journal, Vol 33, pp692-724.

[2] Baumruk, R. (2004) 'The missing link: the role of employee engagement in business success', Workspan, Vol 47, pp48-52.

[3] Richman, A. (2006) 'Everyone wants an engaged workforce how can you create it?'Workspan, Vol 49, pp36-39.

[4] Shaw, K. (2005) 'An engagement strategy process for communicators', Strategic Communication Management, Vol 9, No 3, pp26-29.

[5] Truss, C., Soane, E., Edwards, C., Wisdom, K., Croll, A. and Burnett, J. (2006) Working Life:Employee Attitudes and Engagement 2006. London, CIPD.

[6] Harter, J.K., F.L. Schmidt \& T.L. Hayes (2002). Business-unit-level relationship between employee satisfaction, employee engagement, 
and business outcomes: A meta-analysis. Journal of Applied Psychology, 87 (2), 268-279

[7] Lucey, J. N. Bateman \& P. Hines. (2005). Why major lean transitions have not been sustained. Management Services, 49 (2), 9-14

[8] Development Dimensions International (DDI). (2005). Whitepaper--Driving Employee Engagement. Retrieved August 1, 2005, from www.ddiworld.com

[9] Fleming, J.H., C. Coffman \& J.K. Harter (2005). Manage your human Sigma. Harvard Business Review, 83 (7), 106-115

[10] The Gallup Organization (2005). Employee Engagement: The Employee side of the HumanSigma Equation. Retrieved August 1, 2005, from http://www.gallup.com/content/default.aspx?ci=52.

[11] Wellins, R. \& J. Concelman. (2005). Creating a culture for engagement Workforce Performance Solutions. Retrieved August 1, 2005 from www.WPSmag.com.

[12] Robinson, D., S. P. Perryman \& S. Hayday. (2004). The Drivers of Employee Engagement. IES Report 408. Retrieved August 1, 2005 , from summary.php?id=408.

[13] Anonymous (2005). What does employee engagement look like? The Business Communicator, 5 (8), 1-2

[14] Saks, A.M. (2006) 'Antecedents and consequences of employee engagement', Journal of Managerial Psychology, Vol 21, No 6 , pp600-619.

[15] Robinson, I. (2006) Human Resource Management in Organisations. London, CIPD.

[16] May, D.R. Gilson, R.L. and Harter, L.M. (2004) 'The psychological conditions of meaningfulness, safety and availability and the engagement of the human spirit at work',Journal of Occupational and Organisational Psychology, Vol 77, pp11-37.

[17] Csikszentmihalyi, M. (1990) Flow: The Psychology of Optima Experience. New York, Harper

[18] Kanungo, R.N. (1982) 'Measurement of job and work involvement', Jourmal of Applied Psychology, Vol 67, pp341-349

[19] Roxnowsky, C. \& C. Hulin. (1992). The scientific merit of valid measures of general constructs with special reference to job satisfaction and job withdrawal in Job Satisfaction: How People Feel about Their Jobs and How it Affects their Performance. C.J.Cranny, P.C. Smith and E.F. Stone (Eds.). New York, NY: Lexington Books.

[20] Dansereau, F., Alutto, J., and Yammarino, F. (1984). Theory Testing in Organizational Behavior: The Varient Approach, Englewood Cliffs, NJ Prentice Hall.

[21] Locke, E.A. \& D. Henne ( 1986). Work motivation theories. In C.L. Cooper \& I. Robertson (Eds.) International review of industrial and organizational psychology (pp. 1-35). London: Wiley.

[22] Harter, J.K., F.L. Schmidt \& T.L. Hayes (2002). Business-unit-level relationship between employee satisfaction, employee engagement, and business outcomes: A meta-analysis. Journal of Applied Psychology, 87 (2), 268-279

[23] Ostroff, C. (1992). The relationship between satisfaction, attitudes and performance: An organizational level analysis. Journal of Applied Psychology, 77 (3), 963-974.

[24] Paullay, I.M., G.M. Alliger \& E.F. Stone-Romero (1994). Construct validation of two instruments designed to measure job involvement and work centrality. Journal of Applied Psychology, 79 (2), 224-228.

[25] Pfeffer, J. (1994). Competitive Advantage Through People: Unleashing the Power of the Work Force. Boston: Harvard Business Review Press.

[26] Diefendorff, M.M., D.J. Brown, A.M. Kamin, \& R.G. Lord (2002). Examining the roles of job involvement and work centrality in predicting organizational citizenship behaviors and job performance. Journal of Organizational Behavior 23 (1). 93-108.

[27] Wellins, R. \& J. Concelman. (2005). Creating a culture for engagement Workforce Performance Solutions. Retrieved August 1, 2005 from www.WPSmag.com.

[28] Hackman, J.R. and Oldham, G.R. (1980), Work Redesign, Addison-Wesley, Reading, MA.

[29] Maslach, C., Schaufelli, W.B. and Leiter, M.P. (2001), "Job burnout", Annual Review of Psychology, Vol. 52, pp. 397-422.

[30] Rhoades, L. and Eisenberger, R. (2002), "Perceived organizational support: a review of the literature", Journal of Applied Psychology, Vol 87, pp. 698-714

[31] Rhoades, L., Eisenberger, R. and Armeli, S. (2001), "Affective commitment to the organization: the contribution of perceived organizational support", Journal of Applied Psychology,Vol. 86, pp. 825-36.
[32] Locke, E.A. \& D. Henne ( 1986). Work motivation theories. In C.L. Cooper \& I. Robertson (Eds.) International review of industrial and organizational psychology (pp. 1-35). London: Wiley.

[33] Harter, J.K., F.L. Schmidt \& T.L. Hayes (2002). Business-unit-level relationship between employee satisfaction, employee engagement, and business outcomes: A meta-analysis. Journal of Applied Psychology, 87 (2), 268-279

[34] The Gallup Organization, Washington, D.C

[35] www.jra.co.nz

[36] Corporate Leadership Council (2004). Driving Employee Performance and Retention through Engagement: A Quantitative Analysis of the Effectiveness of Employee Engagement Strategies, CLC, Washington, DC.

[37] Goffman, E. (1961) Encounters: Two Studies in the Sociology of Interaction. Indianapolis,Bobbs-Merrill Co. in Ferguson, A. (2007) 'Employee engagement: Does it exist, and if so,how does it relate to performance, other constructs and individual differences?' [online]Available http://www.lifethatworks.com/Employee-Engagement.prn.pdf [Accessed 20th June 2007]

[38] Diamond, M.A. and Allcorn, S. (1985) 'Psychological dimensions of role use in bureaucratic organisations', in Kahn, W.A. (1990) 'Psychological conditions of personal engagement and disengagement at work', Academy of Management Journal, Vol 33, pp692-724.

[39] Freud, S. (1922) in Ferguson, A. (2007) 'Employee engagement: Does it exist, and if so, how does it relate to performance, other constructs and individual differences?' [online] Available at: http://www.lifethatworks.com/Employee-Engagement.prn.pdf [Accessed 20th June 2007]

[40] Merton, R.K. (1957) Social Theory and Social Structure. New York, Free Press of Glencoe in Ferguson, A. (2007) 'Employee engagement: Does it exist, and if so, how does it relate to performance, other constructs and individual differences?' [online] Available at: http://www.lifethatworks.com/Employee-Engagement.prn.pdf [Accessed 20th June 2007]

[41] Slater, P.E. (1966) Microcosms. New York, Wiley in Ferguson, A (2007) 'Employee engagement: Does it exist, and if so, how does it relate to performance, other constructs and individual differences?' [online] Available at: http://www.lifethatworks.com/EmployeeEngagement.prn.pdf [Accessed 20th June 2007]

[42] Smith, K.K. and Berg, D.N. (1987) Paradoxes of Group Life. San Francisco, Jossey-Bass.

[43] Alderfer, C.P. (1972) Human needs in organisational settings. New York, Free Press of Glencoe.

[44] Maslow, A. (1954) Motivation and Personality. New York, Harper and Row.

[45] Maslach, C. Schaufelli, W.B. and Leiter, M.P. (2001) 'Job burnout', Annual Review of Psychology, Vol 52, pp397-422.

[46] Holbeche, L. and Springett, N. (2003) In Search of Meaning in the Workplace. Horsham, Roffey Park

[47] Cropanzano, R. and Mitchell, M.S. (2005) 'Social exchange theory: an Interdisciplinary review', Journal of Management, Vol 31, pp874-900.

[48] The Gallup Organisation (2004) [online] Available at: www.gallup.com. Accessed 28th June 2007.

[49] ISR (2004) International Survey Research. [Online] Available at: www.isrsurveys.com [Accessed 6th July]

[50] Ott, B. (2007) 'Investors take note: Engagement boosts earnings', The Gallup Management journal, 14th June. [online] Available at: http://web.ebscohost.com/ehost/pdf?vid=4\&hid=21\&sid=8470b965-2 8f0-4f5a-9522-6c297e68b789\%40sessionmgr8 [accessed 2nd July]

[51] Locke, E.A. and Taylor, M.S. (1990) 'Stress, coping, and the meaning of work', in Brief, A. and W.R. Nord (Eds) Meanings of Occupational Work, pp135-170. Lexington, Lexington Books.

[52] Johnson, M. (2004) 'Gallup study reveals workplace disengagement in Thailand', The Gallup Management Journal, 12th May. [online] Available at:http://gmj.gallup.com/content/16306/3/Gallup-Study-Reveals-Work place-Disengagementin. aspx. Accessed 27th July 2007.

[53] Schaufeli, W.B. and Bakker, A.B. (2004) 'Job demands, job resources, and their relationship with burnout and engagement: a multi-sample study', Journal of Organisational Behaviour, Vol 25, pp293-315

[54] Truss, C., Soane, E., Edwards, C., Wisdom, K., Croll, A. and Burnett, J. (2006) Working Life:Employee Attitudes and Engagement 2006. London, CIPD.

[55] Ferguson, A. (2007) 'Employee engagement: Does it exist, and if so, how does it relate to performance, other constructs and individual differences?' [online] Available

at: 
http://www.lifethatworks.com/Employee-Engagement.prn.pdf [Accessed 20th June 2007]

[56] Purcell, J. (2006) Change Agenda, Reflections on Employee Engagement. London, CIPD

[57] Konrad, A.M. (2006) 'Engaging employees through high-involvement work practices’, Ivey Business Journal, March/April, pp1-6.

[58] www.hewitt.com

[59] www.ixia-uk.com

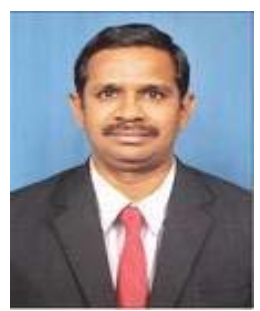

D.Pradeep Kumar M.B.A., Ph.DD. Pradeep Kumar is PROFESSOR HEAD, Department of Management Studies at Madanapalle Institute of Technology and Science, Madanapalle a premier institute in the State of Andhra Pradesh, India. He has 6 years of industry experience and 16years of academic experience, Specialised in HR \& Marketing. He has presented research papers in many national and internationall conferences and more than 15 papers published in national and international journals. He has guided $10 \mathrm{M}$. Phils and presently guiding nearly $10 \mathrm{Ph} . \mathrm{Ds}$. He travelled to Hungary, South Africa and visited the universities there as part of his academic programmes.

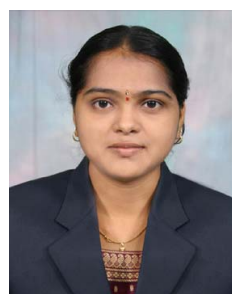

G.Swetha M.B.A, (Ph.D), G. Swetha , Assistant Professor, S.V.College of Engineering, Tirupati ,A.P. She has 5 years of academic experience, specialized in H.R. \& Marketing. 